\title{
Parametric and numerical study of the thermal comportment inside an electrical transformation station located in the south- west of Algeria (city of Bechar)
}

\author{
A Hammadou*, A Missoum, M Elmir \\ Laboratory of Energetic in Arid Zone ENERGARID, University \\ of TAHRI Mohamed Bechar, Algeria
}

\begin{abstract}
Due to the significant increase in temperature in summer in the Saharan zone in this case the town of Bechar, electric power medium voltage to low voltage substations (MV / LV) installed by companies distribution of electricity and gas (SONELGAZ) undergo additional constraints compared to those installed in the north, due to overheating which reduces the life of the plant and cause adverse judgments to clients.

In this context, the work presented a numerical study the type post of public distribution, has content a transformer and taking into account the measures taken by the outdoor temperature weather station lab ENERGARID. The objective of this study is to analyze the results of the distribution of temperature, aeration and streamline to the inside of the post.
\end{abstract}

\section{INTRODUCTION}

Nowadays, thermal efficiency and the reduction of energy consumption have become very important research topics in order to address several concerns that are cited: the fear of a depletion of non-renewable energy sources, pollution and global warming due to the consumption of hydrocarbons ... The envelope acts as a thermal filter that creates a microclimate inside the building, independent of weather fluctuations. The composition of the envelope is a determining element of the characteristics of this filter. As the interior ambiances of the building cannot always meet the comfort requirements of the occupants, the building's response is corrected by heating or air conditioning appliances acting as controlled sources of heat or cold. In all cases, the heating and cooling systems consume energy. The Kyoto commitments to reduce energy consumption and greenhouse gas emissions as well as on housing than the service sector.

Thermal inertia has a positive effect on the indoor conditions of a building during the summer and during the winter. Indeed, the free heat inputs by the sun during the day are stored and then released into the indoor environment later. During the winter, this stored solar heat is transferred to the indoor environment late in the evening thus satisfying part of the heating load while avoiding overheating and user discomfort during periods of strong sunlight. During the summer, the storage of heat in the walls avoids the peaks of the cooling load. Stored heat is gradually released into the interior of the building resulting in a change in the indoor temperature that remains in the range of comfort. This can therefore significantly reduce the energy consumed for air conditioning.

*Corresponding Author: amina_hamad87@yahoo.fr 
Bioclimatic architecture is a building concept that combines the architecture of the house or habitat, the climatic conditions, the construction site and the materials used. A harmony is sought to obtain a habitat designed to be as pleasant in summer as winter. The design of a house for example is designed to capture solar radiation in winter and protect itself in summer, which allows to make great energy savings (heating, lighting, air conditioning) and to benefit from a high comfort. Beyond a certain limit, the thermal insulation allows at the same time to increase the comfort and to reduce the energy consumption of heating. But that's not all, insulation is also good for the environment because it helps reduce pollutant emissions. Thus, thermal insulation is interesting in practical, economic and ecological terms. It also improves the sound insulation. The techniques used are intended to ensure and guarantee in the habitat a constant internal temperature desired whatever the outside temperature.

The energy consumed for air conditioning is an important part of the energy bill in Algeria, particularly in Bechar, a city in southern Algeria, characterized by its arid climate, with strong seasonal thermal amplitudes, but which imposes long periods of time. air conditioning in the year. The individual building accounts for nearly $70 \%$ of the existing housing and more than $80 \%$ of poorly classified homes in the city of Bechar. These buildings have similar resemblances of the buildings, among others the terracotta brick facades.

The opaque vertical walls are one of the primary sources of loss and the study of the heat transfer in these walls makes it possible to understand the interests of these walls and to choose an adequate thermal insulation. In this work we propose to thermally study a multilayer wall, typical of individual houses in the city of Bechar, in order to understand its dynamic thermal characteristics during different climate seasons. There are three types of walls: the first type is a single wall consisting of $15 \mathrm{~cm}$ thick brick bonded by a mortar on the outside and plaster on the inside, the second type consisting of two brick walls of $10 \mathrm{~cm}$ thick separate by $5 \mathrm{~cm}$ thick polystyrene bonded by a mortar on the outside and plaster on the inside and the third type the same as the previous one by replacing the polystyrene by the air gap.

The objective of this study is to analyze and evaluate the temperature of the different multilayer walls of the typological construction of the region taking into account the climatic conditions during a warmer period of the city of Bechar. For this we use a COMSOL Multiphysics numerical simulation code based on the finite element method.

\section{DESCIPTION OF CASES STUDIED}

Figure 1. shows the studied configuration which consists of an electrical transformer station for public distribution. The geometric dimensions are those typically to the construction standards used by the National Company of Electricity and Gas SONELGAZ length L $=3.60$ $\mathrm{m}$, height $\mathrm{H}=3 \mathrm{~m}$ and openings $1=0.44 \mathrm{~m}$. The external face is subjected to conditions of thermal flow (Temperature and Solar Radiation) of the climate of the city of BECHAR (southwest of Algeria) during the warmer months of July and the interior face has a cold temperature so the soil and the ceiling remain without any heat exchange (adiabatic) and the transformer dissipates a convective heat flow inside the station. Taking into account the heat transfer by conduction in the wall and the two outer and inner faces respectively contains outlet and air inlet openings. 


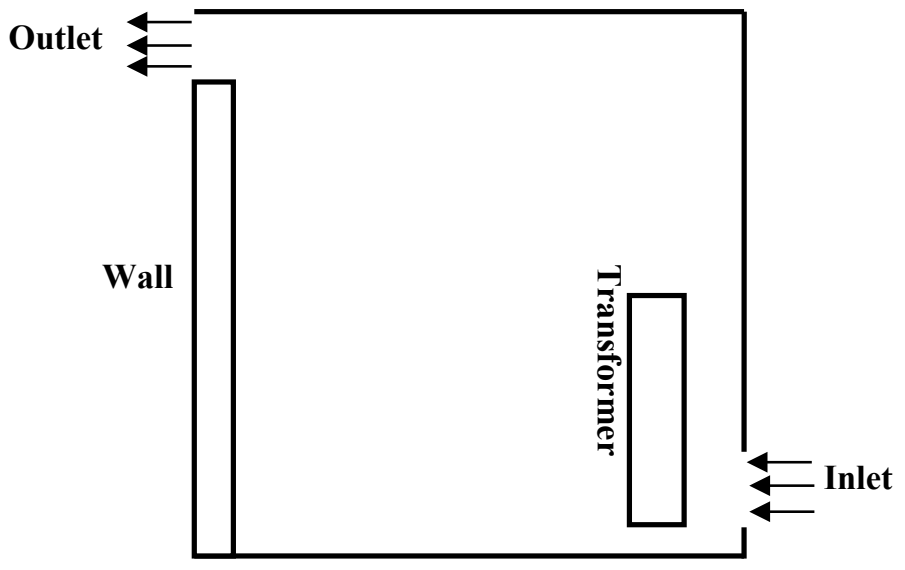

Figure 1. Studied configuration

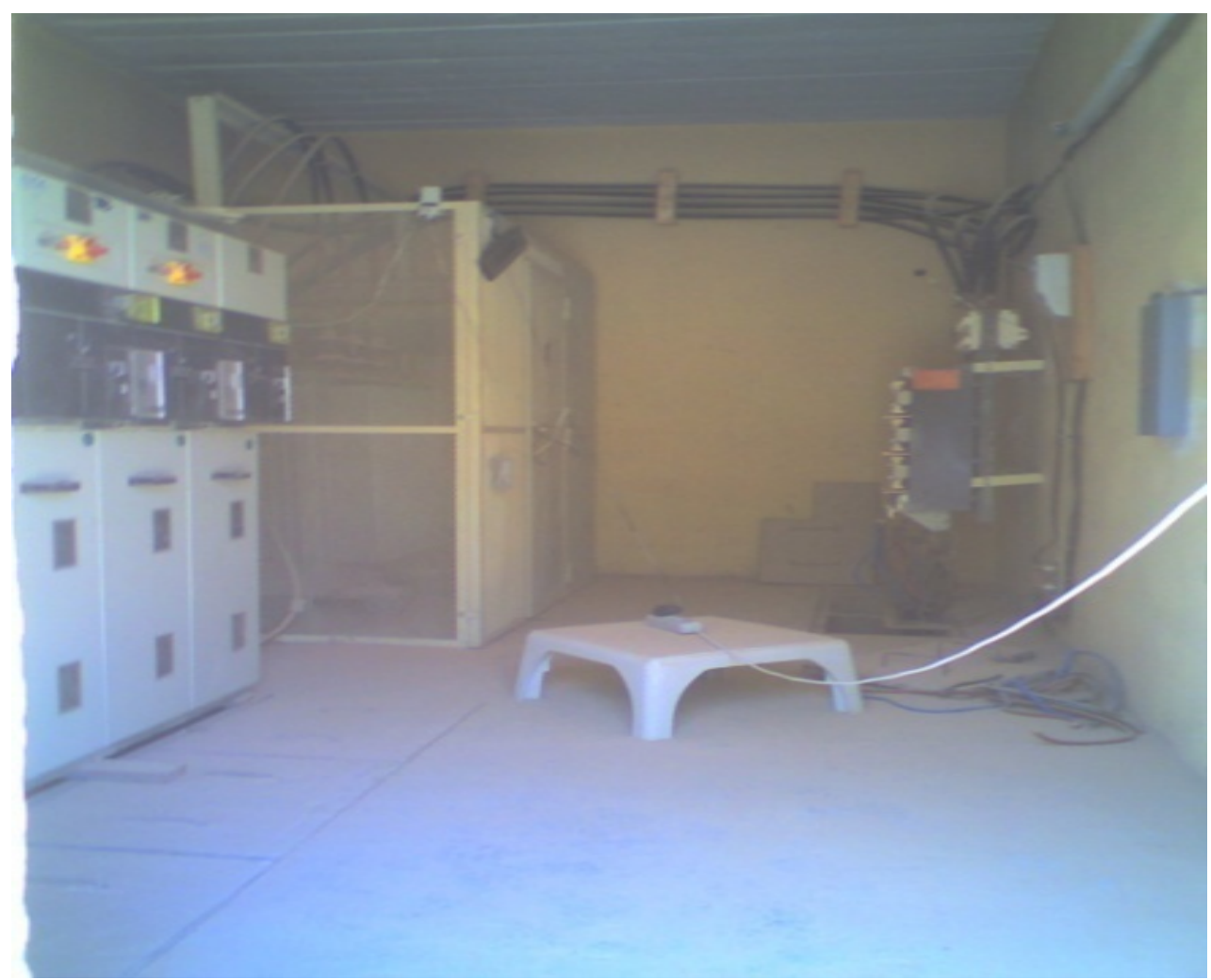

Figure 2. Inside the post MT/BT 


\subsection{Weather conditions}

The boundary conditions considered in this study are the summer climatic conditions of the city of Bechar. During the summer period, the Bechar region is characterized by a hot and dry climate, and a very important daytime thermal amplitude. Indeed, the maximum temperatures can reach $50^{\circ} \mathrm{C}$ in the day, for a diurnal amplitude around $15^{\circ} \mathrm{C}$ and a strong sunshine which reaches $1000 \mathrm{~W} / \mathrm{m}^{2}$ (figures 2 and 3 ). These climatic conditions in turn encourage discomfort.

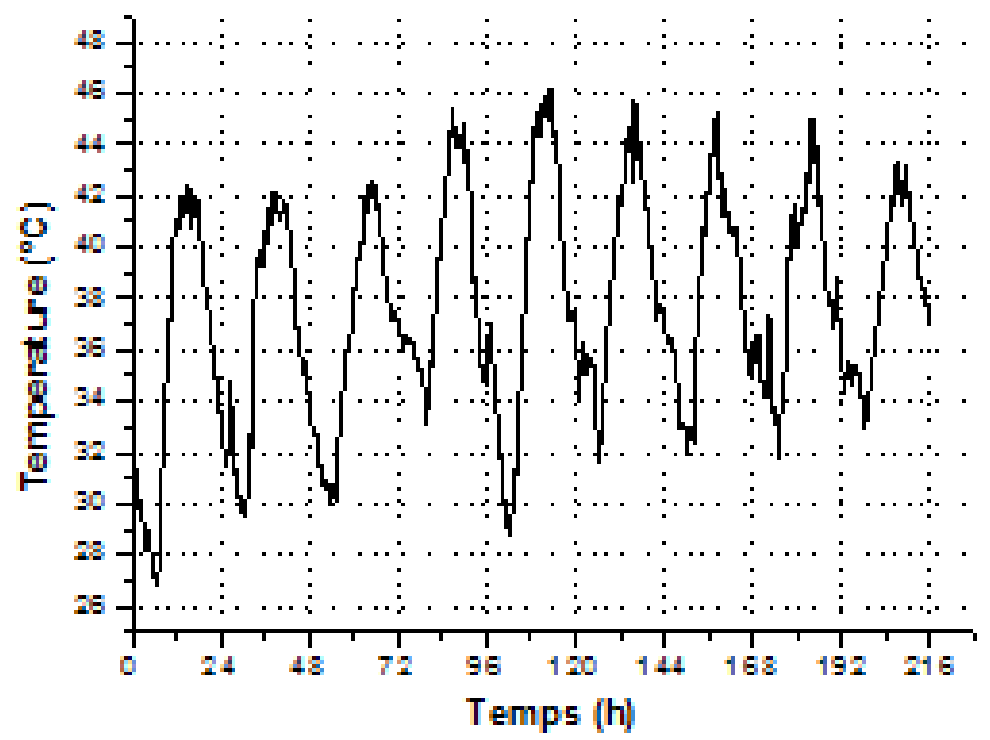

Figure 3. Temperature mesured from 23 to 31 July 2015

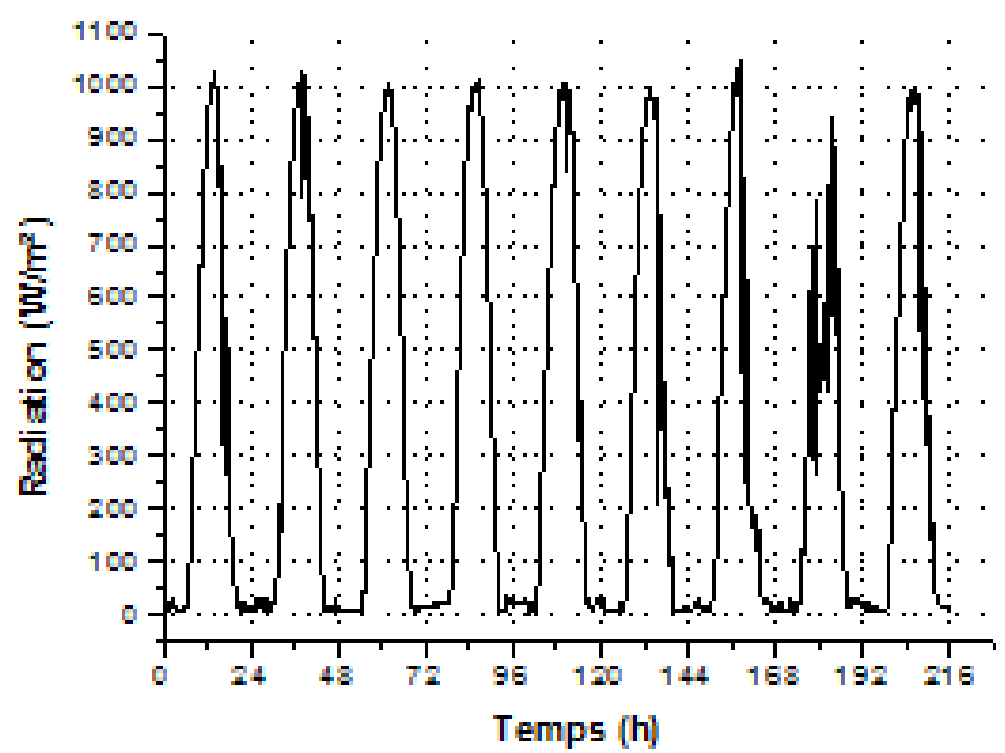

Figure 4. Radiation measured from 23 to $31 \mathrm{Jul}$ 


\subsection{Mathematical model}

The continuity, momentum and energy equations for a two dimensional laminar flow of an incompressible Newtonian fluid are written using following assumptions: there is no viscous dissipation, the gravity acts in the vertical direction, fluid properties are constant and fluid density variations are neglected except in the buoyancy term (the Boussinesq approximation). Following non-dimensional variables are defined:

$$
x=\frac{X}{H} ; y=\frac{Y}{H} ; u=\frac{U}{U_{0}} ; v=\frac{V}{U_{0}} ; p=\frac{P}{\rho . U_{0}^{2}} ; T=\frac{\theta-\theta_{0}}{\theta_{C}-\theta_{0}}
$$

The non-dimensional governing equations in transient form are obtained as:

$$
\begin{gathered}
\frac{\partial u}{\partial x}+\frac{\partial v}{\partial y}=0 \\
\frac{\partial u}{\partial t}+u \frac{\partial u}{\partial x}+v \frac{\partial u}{\partial y}=-\frac{\partial p}{\partial x}+\frac{1}{R e}\left(\frac{\partial^{2} u}{\partial x^{2}}+\frac{\partial^{2} u}{\partial y^{2}}\right) \\
\frac{\partial v}{\partial t}+u \frac{\partial v}{\partial x}+v \frac{\partial v}{\partial y}=-\frac{\partial p}{\partial y}+\frac{1}{R e}\left(\frac{\partial^{2} v}{\partial x^{2}}+\frac{\partial^{2} v}{\partial y^{2}}\right)+\frac{G r}{R e^{2}} T_{a} \\
\frac{\partial T_{a}}{\partial t}+u \frac{\partial T_{a}}{\partial x}+v \frac{\partial T_{a}}{\partial y}=\frac{1}{R e \cdot P r}\left(\frac{\partial^{2} T_{a}}{\partial x^{2}}+\frac{\partial^{2} T_{a}}{\partial y^{2}}\right)
\end{gathered}
$$

$P r$ is Prandtl number, $R e$ is Reynold number, $G r$ is Grashof number and $R i$ is Richardson number given by:

$$
\operatorname{Pr}=\frac{\gamma}{\alpha} ; \quad R e=\frac{u_{0} H}{\gamma} ; G r=\frac{g \beta\left(T_{C}-T_{0}\right) H^{3}}{\gamma^{2}} ; R i=\frac{G r}{R e^{2}}
$$

The steady-state solutions are obtained from unsteady-state equations, Eqs. (1) - (4). The local and average Nusselt numbers are calculated, respectively, as

$$
\left.\begin{array}{c}
N u_{l o c}=-\frac{\partial T_{a}}{\partial x} \\
N u=\int_{0}^{H} N u_{l o c} d y
\end{array}\right\}
$$

The dimensionless equation of heat conduction in the solid wall is given by:

$$
\frac{\alpha_{\mathrm{a}}}{\alpha_{\mathrm{s}}} \frac{\partial \mathrm{T}_{\mathrm{s}}}{\partial \mathrm{t}}=\frac{\partial^{2} \mathrm{~T}_{\mathrm{s}}}{\partial \mathrm{x}^{2}}+\frac{\partial^{2} \mathrm{~T}_{\mathrm{s}}}{\partial \mathrm{y}^{2}}
$$


The continuity of the temperature and the heat flux at the fluid-wall interfaces gives:

$$
\begin{aligned}
\mathrm{T}_{\mathrm{s}}(\mathrm{x}, \mathrm{y}) & =\mathrm{T}_{\mathrm{a}}(\mathrm{x}, \mathrm{y}) \\
q_{\text {conduction }} & =q_{\text {convection }} \\
\mathrm{k}_{\mathrm{S}} \frac{\partial \mathrm{T}_{\mathrm{S}}}{\partial \mathrm{y}} & =\mathrm{k}_{\mathrm{a}} \frac{\partial \mathrm{T}_{\mathrm{F}}}{\partial \mathrm{y}}
\end{aligned}
$$

\subsection{Boundary conditions:}

The boundary conditions of the system shown in Fig. 1 are as follows:

- No slip condition applies at interior surfaces: $u=v=0$,

- No radiation: $x=0, y=h, q(t)=(T e(t)-T)$,

- With radiation: $x=0, y=h, q(t)=0.02 * q_{r}(t)+(T e-T)$,

- Inlet flow: $T=0$ and $u=1, v=0$,

- Heat convective out flow applies at all exterior transformer surfaces: $q=1-T$,

- Adiabatic: $x=1, y=0$ and $y=0.82$.

\section{NUMERICAL VALIDATION:}

We are studying a test to compare the results of the unidimensional version of the calculation code used COMSOL Multiphysics with some results well known in the literature. This is a problem of an outer monolayer wall of the substation governed by the equation of heat without source term, with constant thermo physical properties.

$$
\left\{\begin{array}{l}
\rho C_{P} \frac{\partial T}{\partial t}=\lambda \frac{\partial^{2} T}{\partial x^{2}} \\
T=T_{C} \text { in } x=0 \\
T=T_{f} \text { in } x=L \\
T=T_{f} \text { at } t=0
\end{array}\right.
$$

The parameters are: $T_{C}=20^{\circ} \mathrm{C}, T_{f}=10^{\circ} \mathrm{C}, L=0.05 \mathrm{~m}, \lambda=36.8 \mathrm{~W} \cdot \mathrm{m}^{-1} \cdot \mathrm{K}^{-1}, \rho=$ $4000 \mathrm{~kg} \cdot \mathrm{m}^{-3}$ and $C p=780 \mathrm{~J} \cdot \mathrm{kg}^{-1} \cdot \mathrm{K}^{-1}$. A low time step $(t=0.01 \mathrm{~s})$ is required to ensure accuracy in the finite difference scheme.

On the other hand, the analytical resolution makes it possible to obtain the following expression of the temperature:

$$
\frac{T(x, t)-T_{F}}{T_{C}-T_{F}}=\left[\operatorname{erfc}\left(\frac{x}{2 \sqrt{\alpha t}}\right)-\operatorname{erfc}\left(\frac{2 L-x}{2 \sqrt{\alpha t}}\right)+\operatorname{erfc}\left(\frac{2 L+x}{2 \sqrt{\alpha t}}\right)\right]
$$

With $\operatorname{erfc}$ the complementary error function and the thermal diffusivity of the medium.

The temperature profile is shown in figure 4 . The numerical results of the calculation code and the analytical solution are superimposed perfectly. 


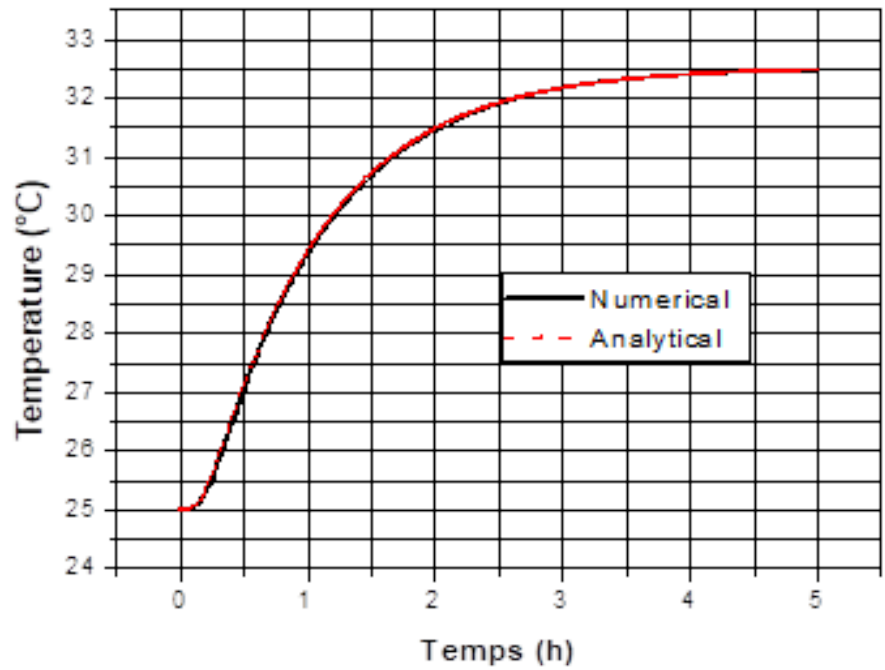

Figure 5. Numerical and analytical temperature profile

\section{NUMERICAL TECHNIQUE}

Numerical results are obtained by solving the system of unsteady differential equations (1)(4), with appropriate boundary and initial conditions, using COMSOL Multiphysics based for Galerkin finite elements method. The computational domain consists of bi-quadratic elements which correspond to 590 elements and a Lagrange quadratic interpolation has been chosen.

\section{RESULTS AND DISCUSSION}

The results obtained in this study were made in two parts:

Part l:

Measurements of temperature in warmer period in this case the month of July of the year 2015 were carried out in collaboration with the company Sonelgaz of the city of Bechar. The results of the climatic data concerning the external parameters (Temperature and Radiation) are recorded by the meteorological station of the Laboratory ENERGARID University of Bechar, as well as the measurements of the air inside the stations were carried out with the help of a micro weather station and also taking pictures by a thermography device. This part of the study was able to develop several convincing results.

\subsection{Distribution of the post temperature}

The evolution of the external and the internal temperature of the studied posts (Figures 6 and 7) have almost the same amplitude variation. The study shows that the external temperature rarely not exceeds $46^{\circ} \mathrm{C}$, but the internal temperature reaches $55^{\circ} \mathrm{C}$. This temperature rises due to the evacuation of a quantity of heat from the transformer to the internal air of a hand position, and the passage of a quantity large flux of heat through the walls inward air. On the other hand, thanks to the combined action of radiation and heating of the transformer and without any recirculation of air change of the post by the ventilation grilles because the calm wind in outside. Furthermore, we remark a temperature in the day $52^{\circ} \mathrm{C}$ and into the night $48^{\circ} \mathrm{C}$. These variations depend on the gradient of the electric charge applied by the transformer. 
The zones have high temperatures participate in the heating of the air inside the post are the transformer and the electrical cable between transformer and low voltage panel (Figure 8). As shown in picture thermo graphic where the highest temperatures are found, in particular the temperature of air in other areas varies between $46^{\circ} \mathrm{C}$ to $54.6^{\circ} \mathrm{C}$.

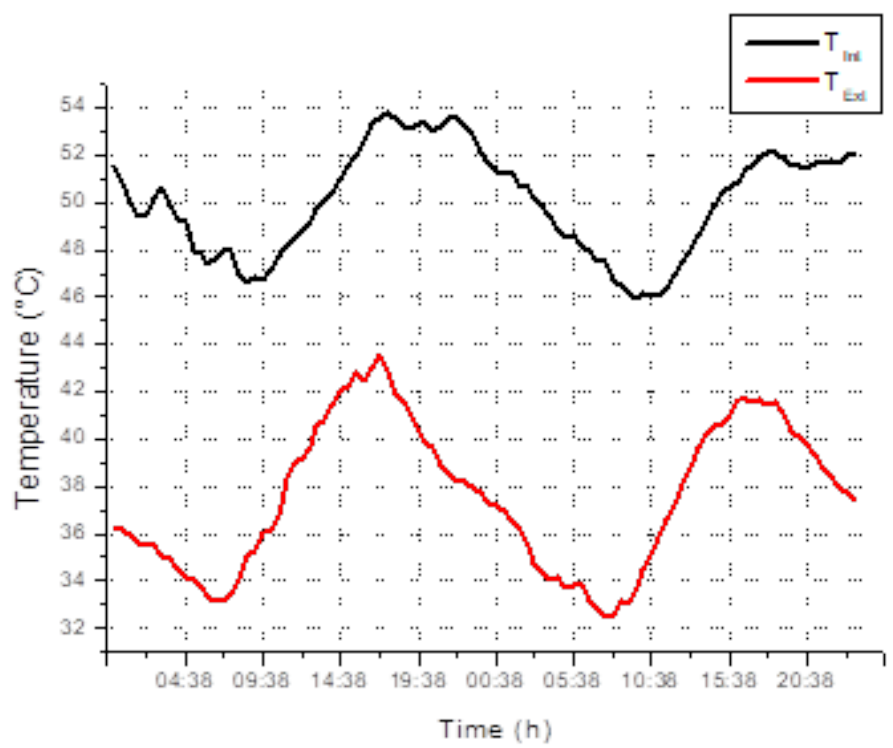

Figure 6. Variation of inside and outside temperature the post 212 from 18 to $19 / 07 / 2014$

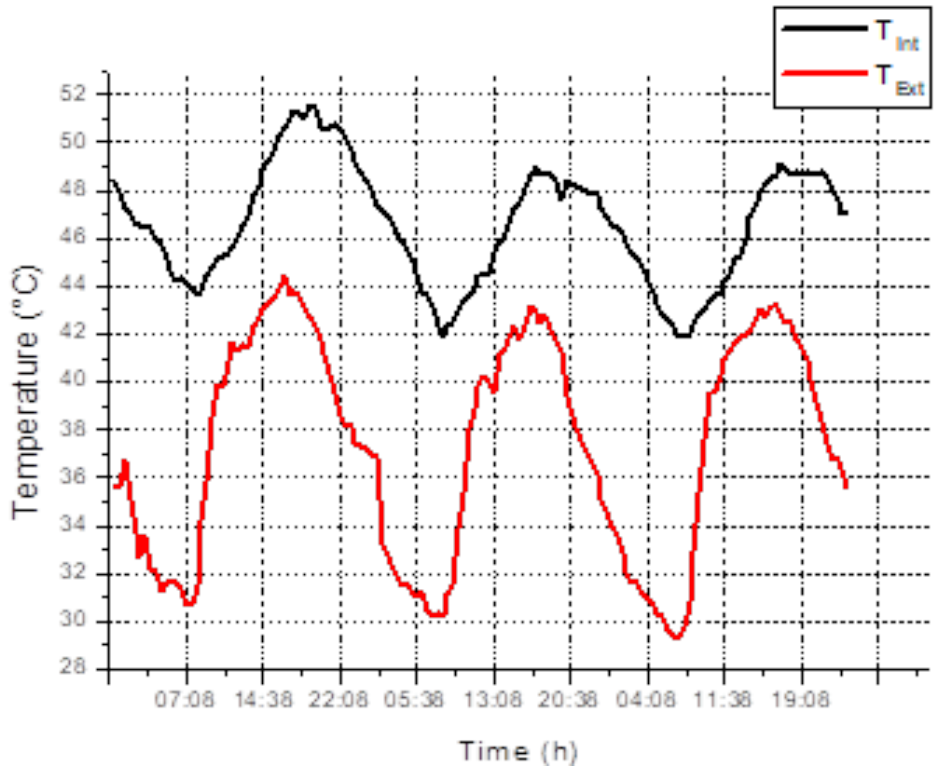

Figure 7. Variation of inside and outside temperature the post 150 from 24 to 26/07/2014 

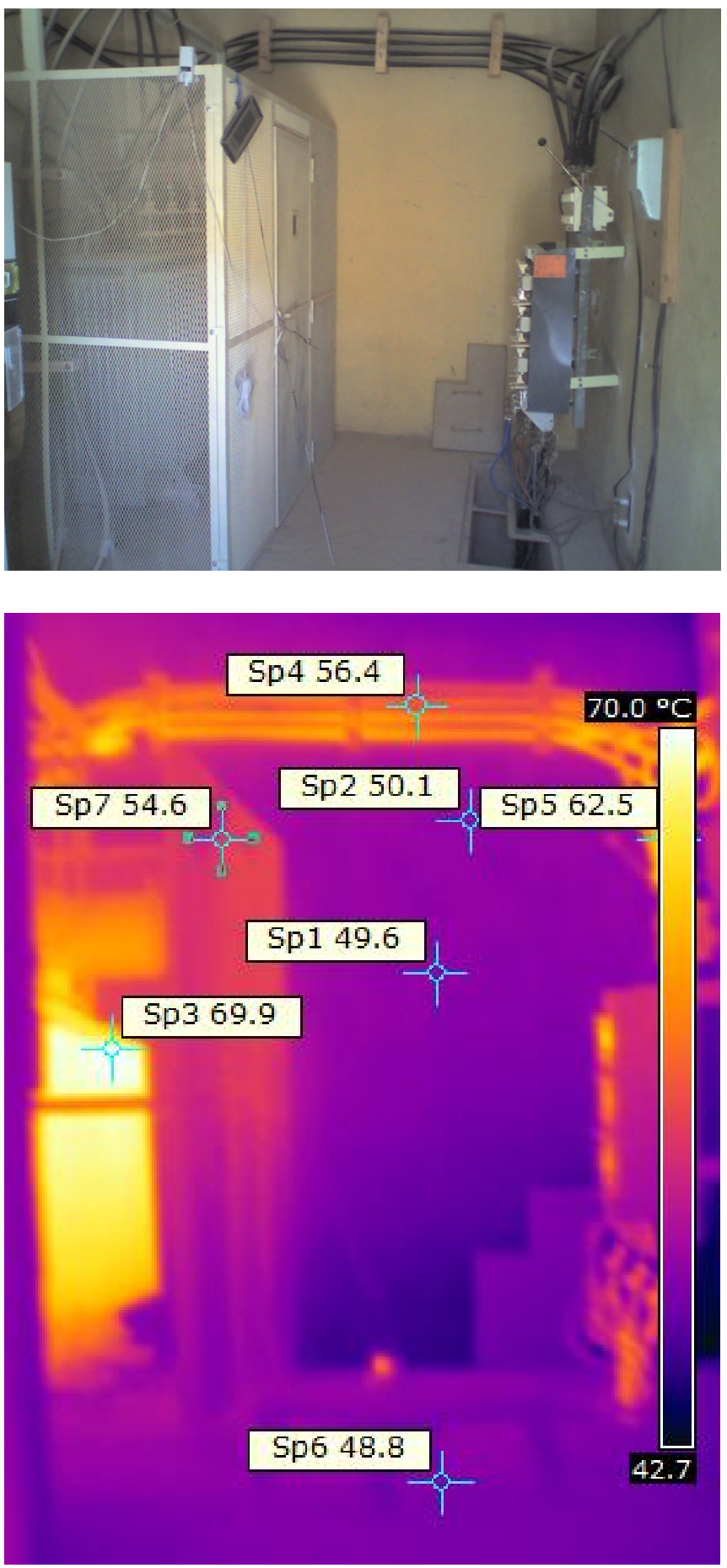

Figure 8. Thermographic image inside the post 212 at 14:30 


\subsection{Distribution of the transformer temperature}

The work of the transformer by an important charge of using dissipates a considerable amount of heat inside the post by Joule effect. This leads to heating of the oil of the transformer tank due to the passage of electric current in the winding (primary and secondary circuits). Although the transformer has fins at the side faces to increase its cooling exchange surface, however, it is found that the distribution of the transformer temperature is very high, due to the Imprisonment of the hot air inside the post without any evacuation of this air by the grilles.

Figure 9 shows the thermo graphic photo of the transformer and the temperature distribution in the wall of the transformer to two places at 14:30 in 27.07.2014. Side electrical terminals and side face. The temperature distribution transformer TR side terminals (upper part) varies between $84^{\circ} \mathrm{C}$ and $85^{\circ} \mathrm{C}$. Against by the temperature of the side face is between $82^{\circ} \mathrm{C}$ and $84^{\circ} \mathrm{C}$, these oscillations have almost $2^{\circ} \mathrm{C}$ maximum peak. Moreover, we remark a net decrease in temperature is noted with respect to the terminals surface side. The oscillations and the temperature decrease is due to the existence of the fins.

\section{Part II:}

The second part of the study presented the numerical results of a substation with typical dimensions implanted by Sonelgaz standards contains an electrical energy transformer that transforms electricity from medium voltage to low voltage (MV/BT).

The results obtained from the studied position with a dimensional geometric parameters $L=1, H=0.82$ and $e=0.06$, the boundary conditions are the climatic data of the city of Bechar which have been imposed in the form of heat flux on the outer surface. from the wall for two different cases a flux without radiation and the other with solar radiation. The Rayleigh number is varied from 103 to 106 and the Reynolds number is 10,50 and 100 in order to present the results obtained in isothermal form, current lines, transfer rate and temperature profile.

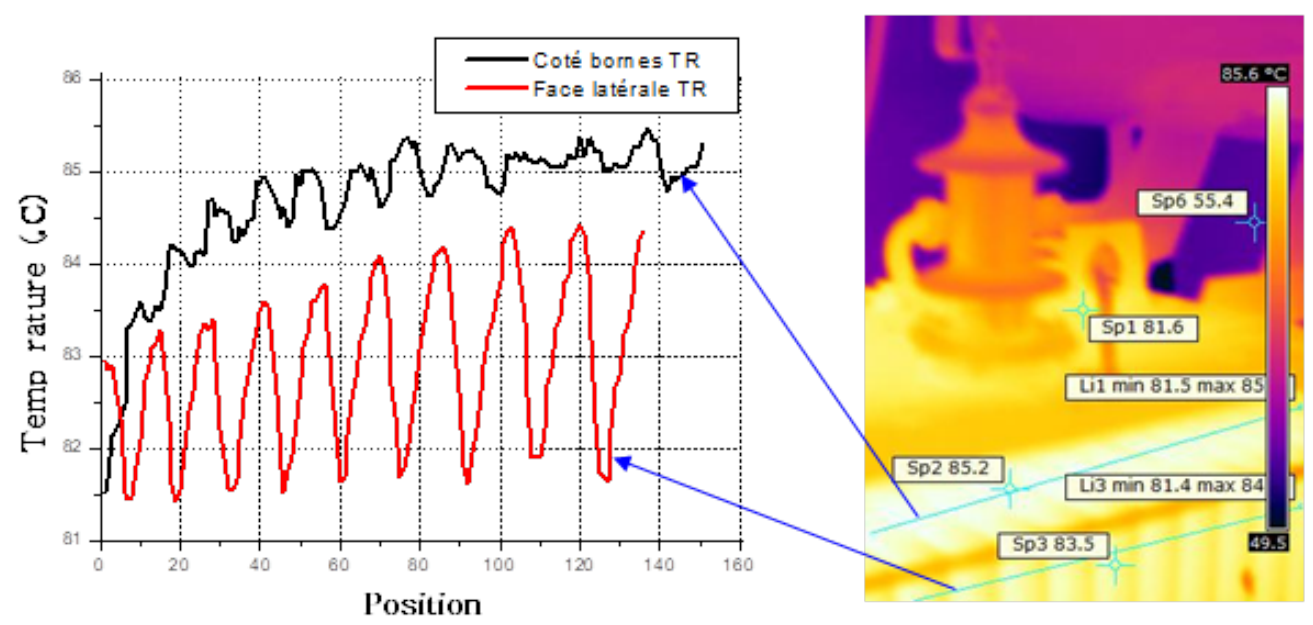

Figure 9. The thermographic image of the transformer and the temperature distribution in the wall of the transformer to two locations at 14:30: side electrical terminals and side face 


\subsection{Thermo-fluid characteristics}

The variation of the current lines for different numbers of Ra and Re with an imposed flux with and without heat radiation is shown in Figures (10 and 12) The entire station is occupied by three zones. The recirculation cells at the top represent the hot air being evacuated and the central cell enlarges thus shrinks actually increasing the air velocity $(\mathrm{Re})$ in order to facilitate the regeneration of the air inside the station; the second part of the recirculation cells located near the outer face of the station represent the air passing through the inner face as it increases the $\mathrm{Re}$ and $\mathrm{Ra}$, the air circulation at the center of the station widens by increasing of the buoyancy force that is to say that the convection is dominant. Therefore, the recirculation zone surrounded by the transformer (hot source) conduction is dominant, so airflow is important by increasing the Re and $\mathrm{Ra}$. When the Ra gradually increases for each Re, the size of the vortex of the exit (opening at the top) situated below that of the part at the top becomes more and more important month, and consequently the size of the one weakened considerably. In addition, it is noted that the open vortices are moved towards the opening of the air outlet of the station, and that the vortex structure is more and more deformed, thus giving an elliptical shape.

The isotherms for different numbers of $\mathrm{Re}$ and $\mathrm{Ra}$ with an imposed heat flux with and without heat radiation is shown in Figures (11 and 13). Note that the high temperatures are localized in narrow spaces in the vicinity of the transformer which correspond to the thickness of the thermal boundary layers, also in the hot wall of the station which are largely influenced by the number of Ra and Re. This leads to an intensification of heat exchange by conduction at this location. Beyond these two areas, thermal stratification appears where convection is dominant. This stratification is most apparent in the upper part of the station. heat transfer increases, so the flow increases, and convection increases and dominates conduction.

\subsection{Heat Transfer Characteristics}

Figures 14 and 15 illustrate the variation of the average transfer rate as a function of the Rayleigh numbers for different Reynolds values for the two faces of the outer and inner wall. For both heating cases, the average heat transfer rate decreases linearly by increasing Ra for the value of $\operatorname{Re}=10$. That is, actually increasing the temperature in the wall with a low speed of the indoor air, there is a decrease in the heat transfer rate which is explained that the mode of transfer by conduction is more dominant. Consequently, for the other two values of $\mathrm{Re}=$ 50 and 100, there is a marked increase in mean $\mathrm{Nu}$ with the increase of Ra. Nevertheless, in the outer face of the wall the increase in the rate of transfer is increased with the increase of the number of Re. On the other hand, there is a decrease of mean $\mathrm{N}$ for $\mathrm{Re}=50$ and 100 along the inner face for the two cases of heating with the increase of Ra signifying that the speed of the indoor air increases the transfer rate dimunié and also this denier believes with Ra the transfer by convection is dominant. There is a marked increase in the value of the transfer rate for the case of radiant heating than that without radiation. 

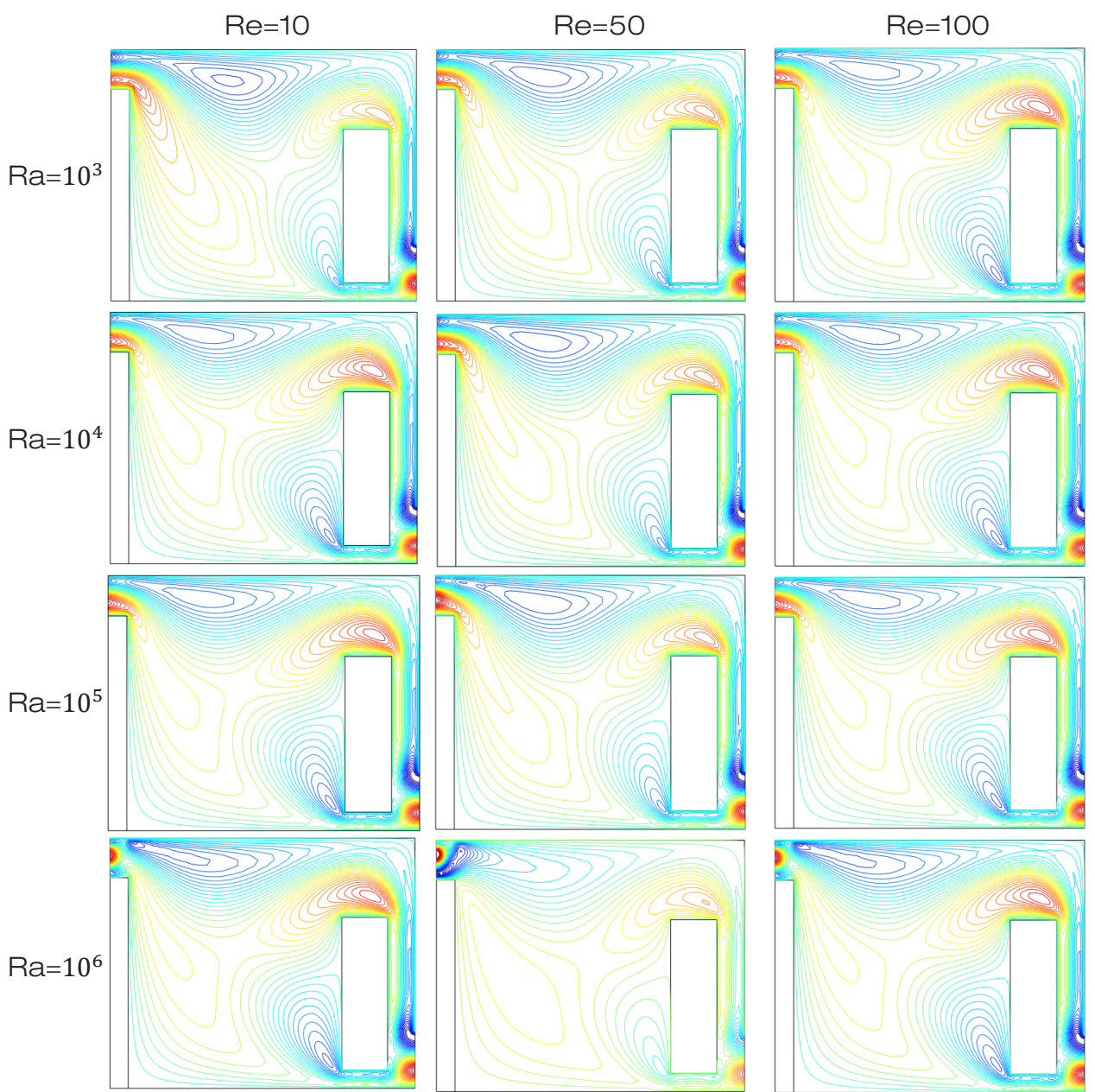

Figure 10. Variation of the streamlines for different Reynolds and Rayleigh numbers in the case without radiation. 


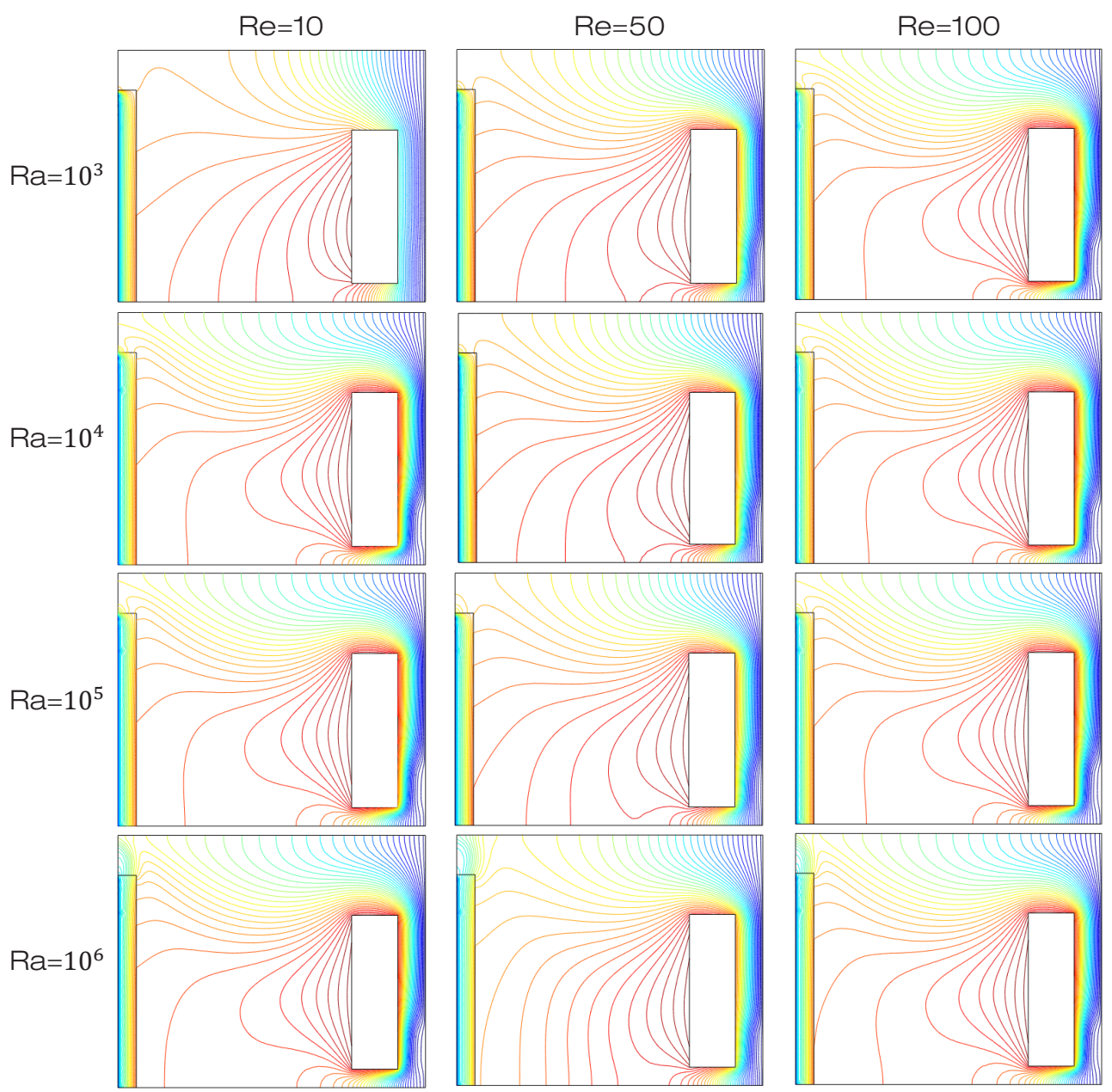

Figure 11. Variation of the isothermal lines for different Reynolds and Rayleigh numbers in the case without radiation. 

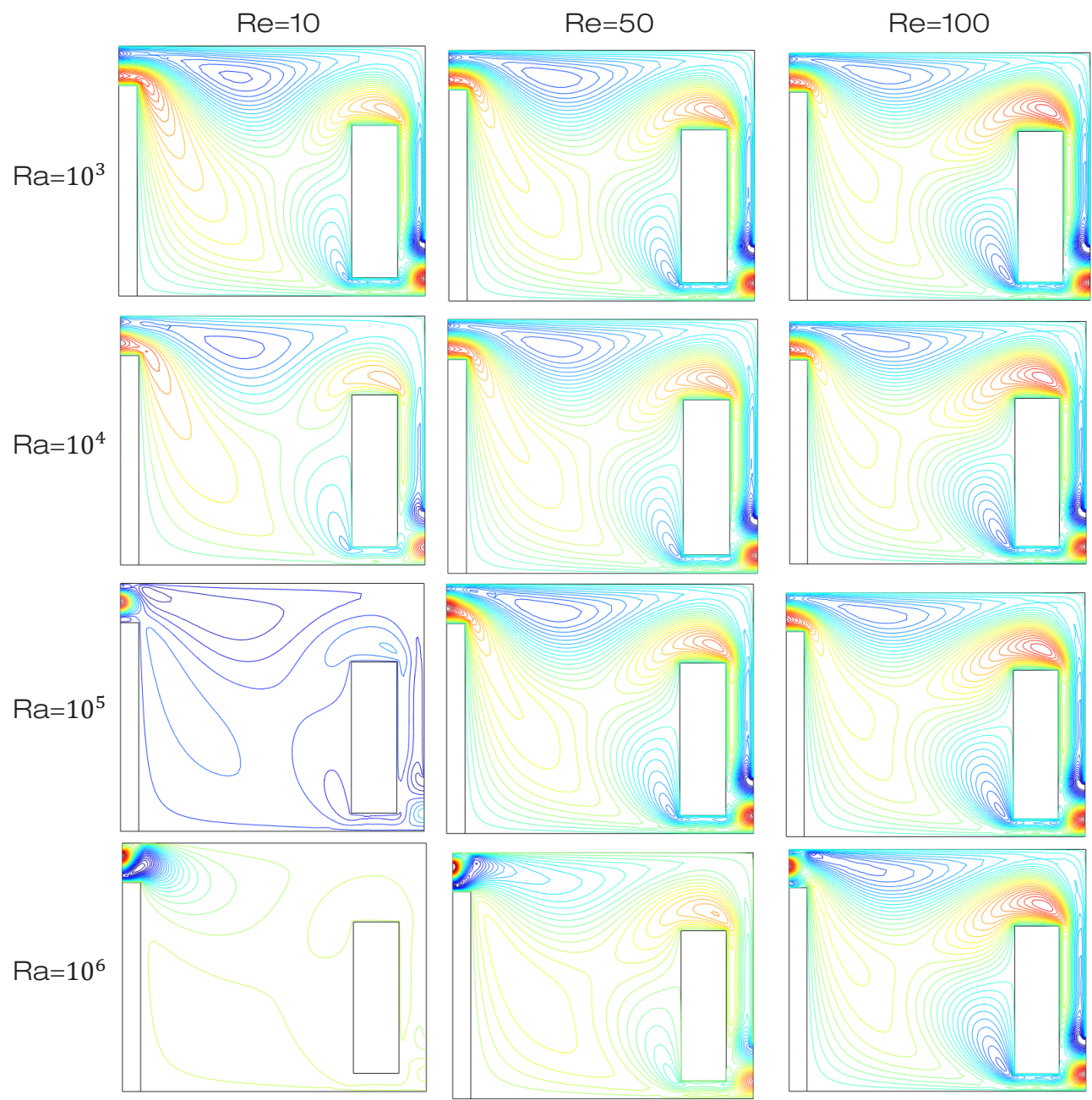

Figure 12: Variation of the streamlines for different Reynolds and Rayleigh numbers in the case with radiation 


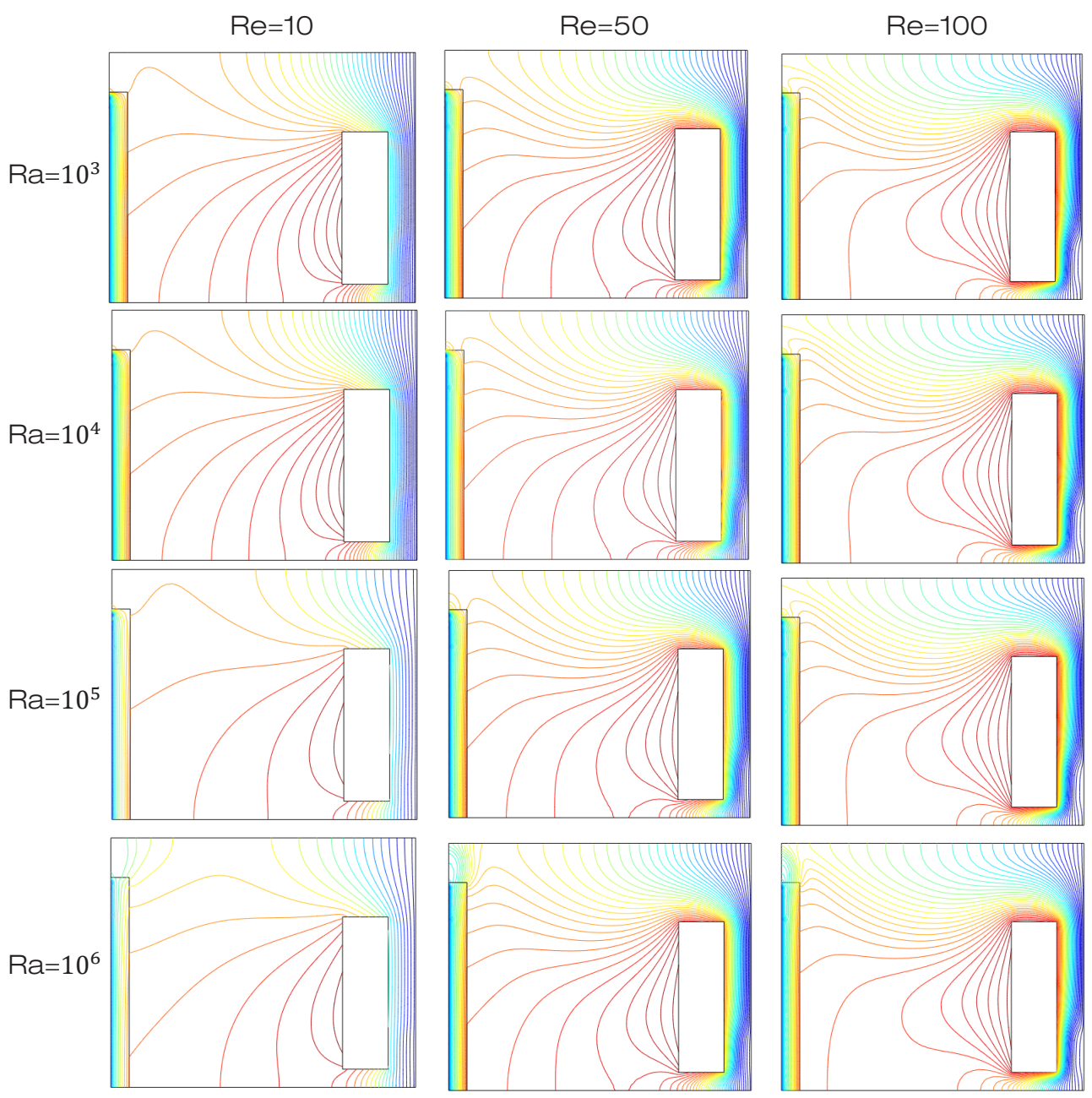

Figure 13: Variation of the isothermal lines for different Reynolds and Rayleigh numbers in the case with radiation 


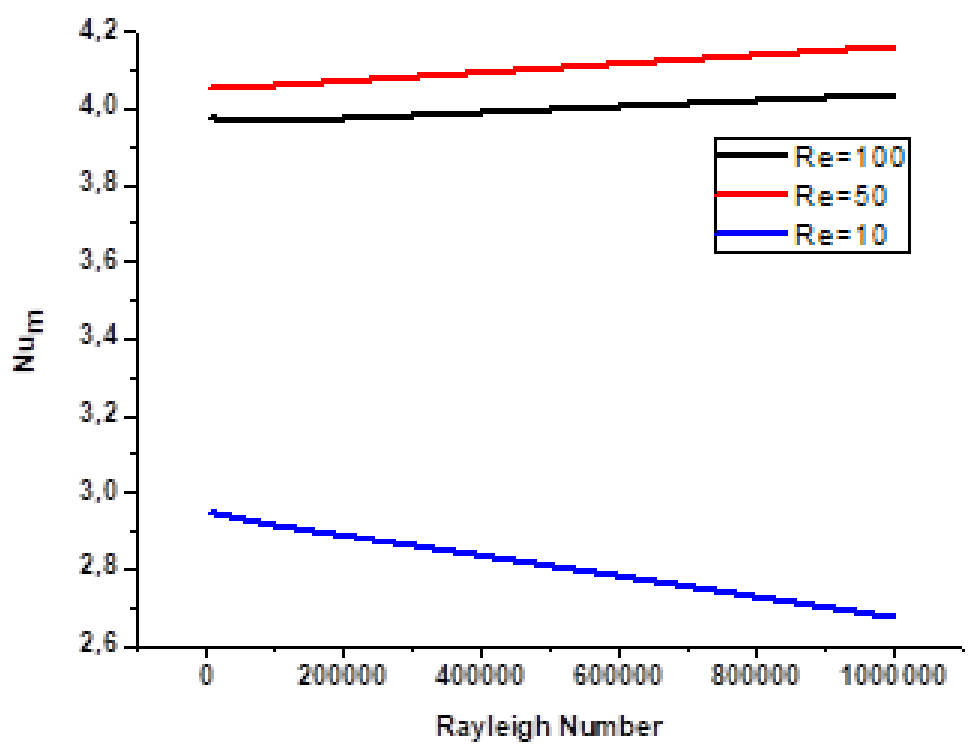

(a)

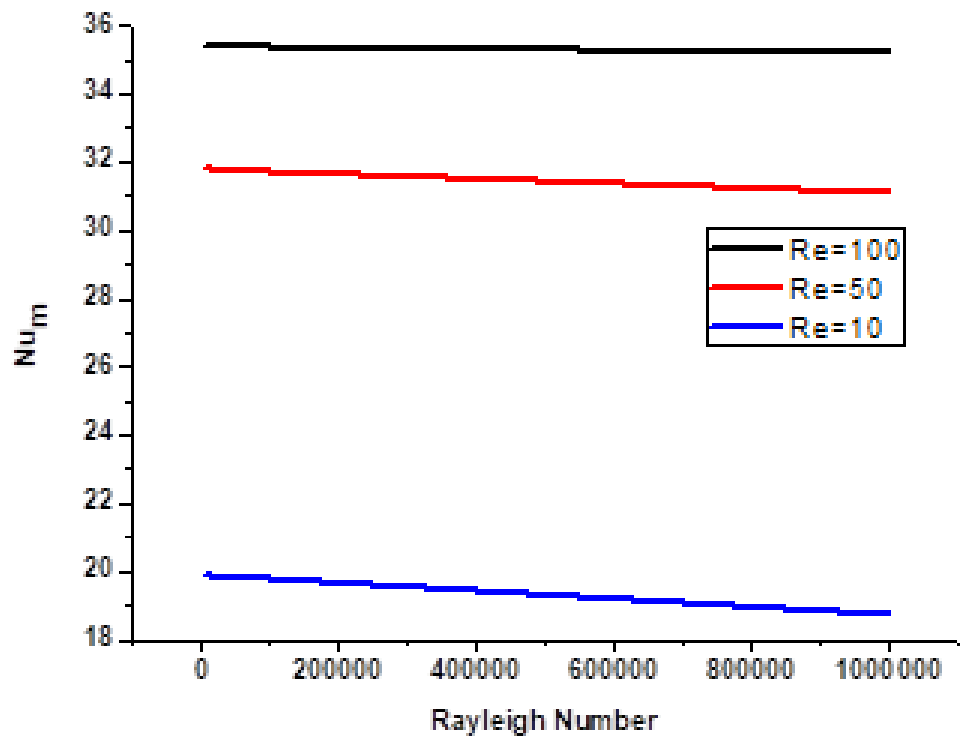

(b)

Figure 14. Average heat transfer rate as a function of Ra for different heat-radiated heating from: (a) Inner face, (b) Outer face 


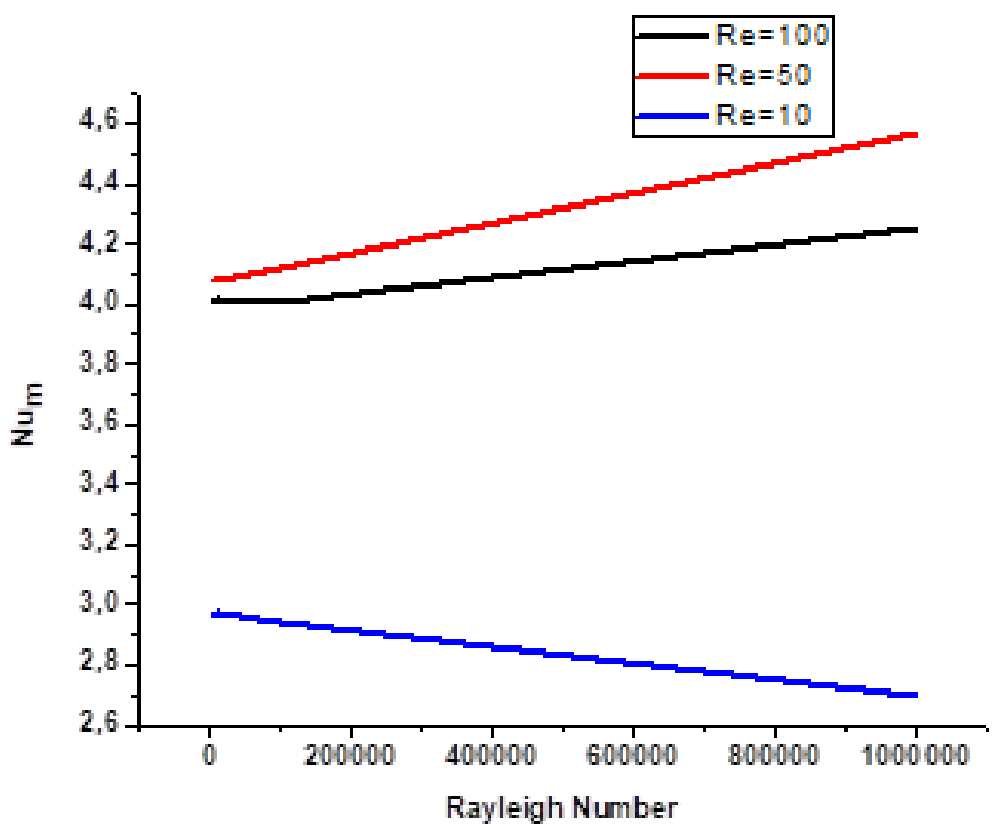

(a)

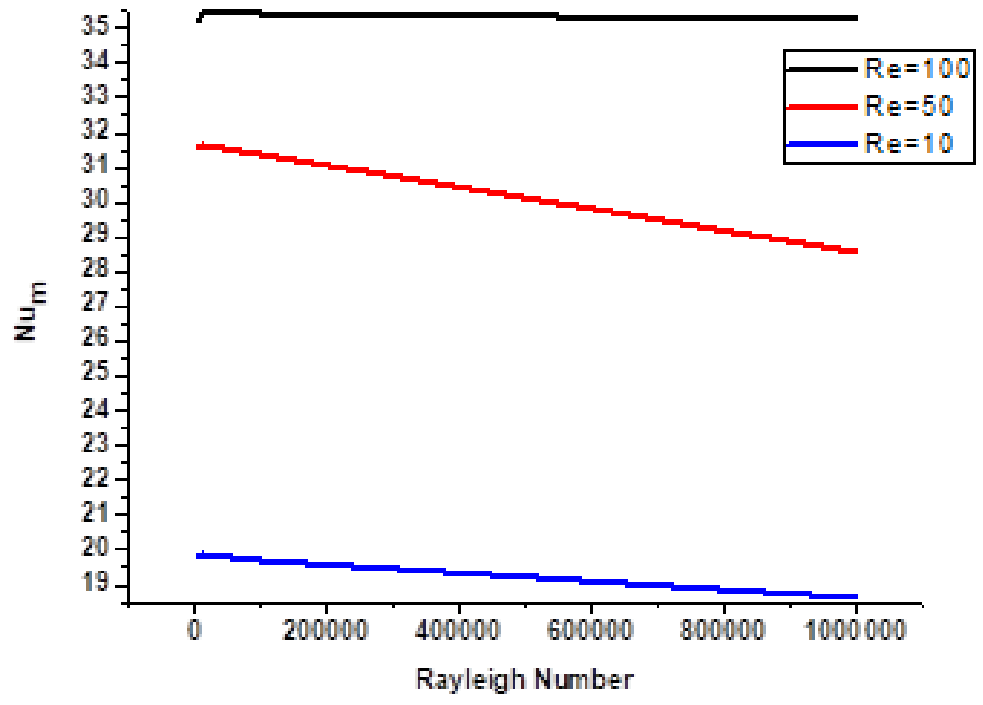

(b)

Figure 15 Average heat transfer rate as a function of Ra for different Re heating without heat radiation from: (a) Inner face, (b) Outer face 


\section{CONCLUSION}

The study presented in this work is on laminar mixed convection in an electrical transformer station intended for public distribution, equipped with two openings and a transformer. The vertical left side wall of the post is brought to a cold temperature and the right wall (near heating body) is subjected to a hot temperature, while the other walls are considered to be adiabatic. For our numerical simulation we presented the current lines and curves with an isothermal speed are maximum one hand, and if the speed is further minimized. It is found that much of the air recirculation position level is lending the wall and the body also heating the air circulation is faster in speed if the input is higher following the renewal of air. Moreover, it is concluded that the temperature distribution follows and consistent airflow. Finally; we see that the heat transfer by conduction is predominant if the speed is low in the case against the high-speed convection is more important.

\section{REFERENCES}

[1] Ostrach, S., 1972, "Natural Convection in Enclosures," In Advances in Heat Transfer, (eds. J. P. Hartnett and T F. Irvine), Vol. 8, pp. 161-227.

[2] Catton, I., 1978, "Natural Convection in Enclosures," Proc. 6th Int. Heat Transfer Conf., Vol. 2, pp. 13-31.

[3] Kulack, F. A., Catton, I., Chen, C. F., and Edwards, D. K., 1982, "Fluid Layers," Proc. of a Workshop on Natural Convection, (eds. Yang, K. T. and Lioyd, J.R.) July 18-21, reckenridge, Colorado.

[4] Baker, L., Faw, R. E., and Kulaeki, F. A., 1976, "Post Accident Heat Removal - Part 1: heat Transfer within an Internally Heated, Non-boiling Liquid Layer," Nucl. Sci. Eng., Vol. 61, pp. 222-230.

[5] Cheung, F. B., 1978, "Correlation Equation for Turbulent Thermal Convection in a Horizontal Layer Heated Internally and From Below," J. Heat Transfer,Vol. 100, pp. 416422.

[6] Kikuehi, Y., Kawasaki, T., and Shiyoma, T., 1982, "Thermal Convection in a Horizontal Fluid Layer Heated Internally and From Below," Int. J. Heat Mass Transfer, Vol. 25, pp. 363-370.

[7] Boon-Long, P., Lester, T. W., and Faw, R. E., 1979, "Convective Heat Transfer in an Internally Heated Horizontal Fluid Layer with Unequal Boundary Temperatures," Int. J. Heat Mass Transfer, Vol. 22, pp. 437-445.

[8] Suo-Anttila, A. J., and Catton, I., 1975, "The Effect of a Stabilizing Temperature Gradient on Heat Transfer from a Molten Fuel Layer with Volumetric Heating," J. Heat Transfer, Vol. 97, pp. 544-548.

[9] Suo-Anttila, A. J., and Catton, I., 1976, "An Experimental Study of a Horizontal Layer of Fluid with Volumetric Heating and Unequal Surface Temperatures," 16th National Heat transfer Conference, St. Louis, Paper No. AICHE-5.

[10] Steinberner, U., Reinke, H. H., 1978, "Turbulent Buoyancy Convection Heat Transfer with Internal Heat Source," Proc., 6th International Heat Transfer Conference, Toronto, Canada, August 7-11, Hemisphere Publishing Corp., Washington, DC, NC- 21, Vol. 2, pp. 305-311.

[11] Kulacki, F. A., and Goldstein, R. J., 1972, "Thermal Convection in a Horizontal Fluid Layer with Uniform Volumetric Energy Sources," J. Fluid Mech., Vol. 55, pp. 271-287. 
[12]NANSTEEL, M., R. GREIF (1981) Natural convection in undivided and partially divided rectangular enclosures, Transactions of ASME, Journal of heat transfer, Vol. 103, pp. 623-629.

[13] A. MISSOUM, M. ELMIR and M. BOUANINI, Numerical simulation of heat transfer through the building facades of buildings located in the city of Bechar. Int. Jnl. of Multiphysics Volume 10 Number 4 2016, pp. 441-450. 
380 